\title{
Elaborating Data Intensive Research Methods through Researcher-Practitioner Partnerships
}

\author{
Mingyu Feng \\ SRI International \\ 333 Ravenswood Ave \\ Menlo Park, CA \\ mingyu.feng@sri.com
}

\author{
Andrew E. Krumm \\ SRI International \\ 333 Ravenswood Ave \\ Menlo Park, CA \\ andrew.krumm@sri.com
}

\author{
Alex J. Bowers \\ Columbia University \\ 525 West 120th St. \\ New York, NY 10027 \\ bowers@tc.edu
}

\author{
Timothy Podkul \\ SRI International \\ 333 Ravenswood Ave \\ Menlo Park, CA \\ timothy.podkul@sri.com
}

\begin{abstract}
Technologies used by teachers and students generate vast amounts of data that can be analyzed to provide insights into improving teaching and learning. However, practitioners are left out of the process. We describe the development of an approach by which researchers and practitioners can work together to use data intensive research methods to launch improvement efforts within schools. This paper describes elements of the first year of a researcher-practitioner partnership, highlighting initial findings, challenges, and strategies for overcoming these challenges.
\end{abstract}

\section{Categories and Subject Descriptors}

K.3.m [Computers and Education]: Miscellaneous.

\section{General Terms}

Measurement, Design, Human Factors.

\section{Keywords}

Data intensive research, researcher-practitioner partnership, learning analytics

\section{INTRODUCTION}

Multiple technologies, such as learning management systems, tutoring systems, digital curriculums, and open-access, supplemental instructional resources, are regularly used in schools. Many of these systems track students' use, thus providing a rich data stream that can be analyzed to better understand teaching and learning [e.g. 1, 11]. However, often missing from the current research landscape is the voice of practitioners. In many ways, the field is driven by solutions (e.g., dashboards and data mining techniques) looking for problems $[5,6,17]$, with little explication on how to productively work with practitioners in a collaborative way. Thus, our focus is on describing the process of developing research-practice partnerships where the voice and needs of practitioners drive the collaborative inquiry [8]. In this paper, we report on aspects of the first year of a project that sought to develop a series of repeatable and scalable processes to support researchers and practitioners collaboratively engage in data intensive research. To begin developing tools, routines, and processes for supporting researchers and practitioners in working together, the approach documented in this paper builds on a research-practice partnership between researchers and practitioners at a charter management organization $(\mathrm{CMO})$

Permission to make digital or hard copies of part or all of this work for personal or classroom use is granted without fee provided that copies are not made or distributed for profit or commercial advantage and that copies bear this notice and the full citation on the first page. Copyrights for third-party components of this work must be honored. For all other uses, contact the Owner/Author.

Copyright is held by the owner/author(s).

$L A K^{\prime} 16$, April 25-29, 2016, Edinburgh, United Kingdom

(a) 2016 ACM 978-1-4503-4190-5/16/04.

DOI: http://dx.doi.org/10.1145/2883851.2883908 operating in California. ${ }^{1}$ The CMO serves diverse students, uses advanced technologies, and has a strong commitment to making data-driven instructional decisions. Through a customized online platform, students access most of their learning resources across all grades and subject areas. Students use the platform in mostly self-directed ways, with monitoring and support from teachers.

Multiple researchers have documented how practitioners can effectively use standardized test scores, grades, and behavioral infractions (e.g., [2, 7]). Researchers have also demonstrated how to use data intensive methods to identify patterns among these same variables (e.g., [3, 4]). A next step for data intensive research is to engage practitioners earlier in the process, building on their insights in shaping analyses to ensure buy-in from both researchers and practitioners [8]. This project uses a design based research approach [15] and theories from organizational and learning sciences to inform the development and refinement of partnership activities. As this paper demonstrates, a partnershipbased approach can be effective for developing and sustaining change efforts in schools because it can aid practitioners in developing new knowledge and skills applicable to future problems and datasets after the partnership ends [9].

\section{UNDERSTANDING NEEDS AND CONTEXT}

We engaged in an iterative cycle of needs analyses by jointly identifying pressing problems of practice facing the CMO. We started the process with joint meetings that involved researchers and a representative team from the CMO including principals, teacher professional development leads, and members of the technology team. The research team initially facilitated a "blue sky," ideation activity where researchers and practitioners brainstormed potential questions. The partnership then iteratively triaged and refined "blue sky" questions. Questions were selected based on the benefits of answering a question in relation to potential costs for students, teachers, or administrators. The entire process led to a number of focus areas and research questions that were meaningful to all audience and do-able given the constraints of time and data quality.

Another important early task was to better understand the CMO's context, which included (1) discerning how students interact with teachers and content and (2) identifying ways in which teachers and administrators currently use data (i.e., what is being looked at and when?). Researchers attended professional development sessions, exchanged emails, and conducted meetings to clarify what instruction looks. CMO staff walked researchers through the process they use to manage, analyze, and report on data for various audiences. One key takeaway from these efforts was that managing and merging datasets was a particular pain point for CMO staff and one that prohibited potentially useful

${ }^{1}$ In the United States, a CMO is like a traditional K-12 school district in that they are public schools; yet they operate under a uniquely defined "charter," the specifics of constitutes a charter vary by states. 
analyses. Moreover, from a teacher's perspective, data was shown to them on how well students did (e.g., assessment scores) and not necessarily what they were doing (e.g., resources accessed).

Although the processes described above took significant time and effort, it was extremely important for the partnership and for later data analysis work. Data analysts often have a strong desire to jump in to mine the data to look for interesting patterns or make accurate predictions. However, when working with practitioners who face specific challenges, it is important to make sure that researchers have a good understanding of the school context and are answering meaningful questions that practitioners could engage in and are willing and able to take action on.

\section{CAPACITY BUILDING}

The research team conducted preliminary data analyses and through an iterative process, the partnership reviewed results and identified ways data analyses could be integrated into regular work practices in schools. Collaboratively interpreting data with practitioners is an important element of the partnership's capacity building efforts. We scaffolded practitioners' understanding of analyses by explicitly instructing CMO staff on researchers' thinking and the methods that were used to analyze, and visualize data as well as interpret results. Instead of having researchers present results, we organized discussions as hands-on exploration opportunities for CMO staff and encouraged them to try to make sense out of the results using data visualizations, for example, that did not contain the CMO's data in order to promote understanding of the techniques that were employed before engaging with CMOspecific data that used the same visualizations. We also relied on relatively basic data exploration and modeling approaches and supported the interpretation of various representations, such as histograms, scatter plots, trend lines, and box plots.

\section{BUILDING INFRASTRUCTURES}

Throughout the first year of the project, we identified the role of (1) partnership and (2) analytics infrastructures that appeared necessary for supporting collaborative research These supports include the routines and tools that researchers will potentially need to consider in order to effectively collaborate with practitioners. Our experience showed that the key pieces to build a strong partnership include: (1) jointly developed goals that are conditional and revisited; (2) intentional efforts to build capacity and promote sustainability; (3) mutually agreed communication routines, roles, and responsibilities; and (4) long-term data sharing agreements. The second support included the analytics infrastructure that we established during the early stage of the project. Elements of this infrastructure deal with the nuts and bolts of managing files, analyzing data, and reporting on data products. Necessary but not sufficient conditions include (1) a shared understanding of available data and the activity system from which they are drawn and (2) processes for sharing data and data products that are secure and easy to access.

\section{CONCLUSION}

Although the promise of practitioners drawing on data to inform decisions is widely recognized, effective implementation has proven challenging ([e.g. 10,13]). We argue that one way to overcome many of the challenges is to include practitioners as early as possible in the process. However, engaging practitioners intimately in multiple facets of a research project comes with its own challenges. The approach we took was to enhance practitioner's ability to interpret and take action with data and to focus on developing basic infrastructures that can support work long term. The style of inquiry and the school-by-school results of a partnership approach will likely not appeal to all researchers- nor should it. Yet, our efforts show that the skills of researchers can be applied in multiple ways to support practitioners and that researchers can benefit from closer ties to what is happening in classrooms.

\section{ACKNOWLEDGEMENTS}

The research was supported by the NSF, through Grant DRL1444621. The opinions expressed are those of the authors and do not necessarily represent views of the NSF.

\section{REFERENCES}

[1] Baker, R. S. (2013). Learning, Schooling, and Data Analytics. In M. Murphy, S. Redding \& J. Twyman (Eds.), Handbook on innovations in learning. Charlotte, NC: Information Age Publishing.

[2] Boudett, K. P., City, E. A., \& Murnane, R. J. (2013). Data Wise: A step-by-step guide to using assessment results to improve teaching and learning. Revised and expanded edition. Cambridge, MA: Harvard Education Press.

[3] Bowers, A. J. (2010). Analyzing the longitudinal K-12 grading histories of entire cohorts of students: Grades, data driven decision-making, dropping out and hierarchical cluster analysis. Practical Assessment Research and Evaluation, 15, 1-18.

[4] Bowers, A. J., \& Sprott, R. (2012). Examining the Multiple Trajectories Associated with Dropping Out of High School: A Growth Mixture Model Analysis. Journal of Educational Research, 105, 176-195.

[5] Bryk, A. S., Gomez, L., Grunow, A., \& LeMahieu, P. (2015). Learning to improve: How America's schools can get better at getting better. Cambridge, MA: Harvard Education Press.

[6] Cho, V., \& Wayman, J. C. (2015). Districts' Efforts for Data Use and Computer Data Systems: The Role of Sense making in System Use and Implementation. Teachers College Record, 116(2), 1-45.

[7] Coburn, C. E., \& Turner, E. O. (2011). Research on data use: A framework and analysis. Measurement, 9, 173-206.

[8] Coburn, C. E., Penuel, W. R., \& Geil, K. E. (2013). Research-practice partnerships. New York, NY: William T. Grant Foundation.

[9] Coburn, C. E., Russell, J. L., Kaufman, J. H., \& Stein, M. K. (2012). Supporting sustainability: Teachers' advice networks and ambitious instructional reform. American Journal of Education, 119(1), 137-182.

[10] Franke, M. L., Carpenter, T. P., Levi, L., \& Fennema, E. (2001). Capturing teacher's generative growth: A follow-up study of professional development in mathematics. American Education Research Journal, 38(3), 653-690.

[11] Koedinger, K. R., D'Mello, S., McLaughlin, E. A., Pardos, Z. A., \& Rosé, C. P. (2015). Data mining and education. Wiley Interdisciplinary Reviews: Cognitive Science.

[12] Marsh, J. A. (2012). Interventions Promoting Educators' Use of Data: Research Insights and Gaps. Teachers College Record, 114(11), 1-48.

[13] Means, B., Chen, E., Debarger, A., \& Padilla, C. (2010). Teachers' Ability to Use Data to Inform Instruction: Challenges and Supports. Washington, DC: U.S. Department of Education.

[14] Penuel, W. R., \& Martin, C. (2015, April). Design-Based Implementation Research as a Strategy for Expanding Opportunity to Learn in School Districts. Paper presented at the Research Conference of the NCTM, Boston, MA.

[15] Schutt, R., \& O'Neil, C. (2013). Doing Data Science: Straight Talk from the Frontline. Cambridge, MA: O'Reilly. 